\title{
Cmambu
}

\section{ОПРОСНИК «ТИПЫ РЕАГИРОВАНИЯ НА СИТУАЦИЮ ИЗМЕНЕНИЙ» : СТРУКТУРА ШКАЛ И ПСИХОМЕТРИЧЕСКИЕ ПОКАЗАТЕЛИ}

\author{
Е.В. БИТЮЦКАЯ ${ }^{a}$, Т.Ю. БАЗАРОВ ${ }^{\mathrm{a}}$, А.А. КОРНЕЕВ \\ ${ }^{a}$ Московский государственный университет имени М.В. Ломоносова, 119991, Россия, Москва, \\ Ленинские горы, 1
}

\begin{abstract}
Резюме
В статье представлены результаты психометрического анализа нового опросника «Типы реагирования на ситуацию изменений» (ТРСИ). Показано, что большинство современных опросников диагностируют устойчивые характеристики реагирования на изменения и толерантности к неопределенности. При этом ТРСИ является методикой ситуационного типа, позволяющей изучить динамические свойства. В исследовании, проведенном на выборке 565 взрослых респондентов, разработана факторная структура, определены возрастные и половые особенности реагирования на ситуацию изменений, проверена конвергентная валидность методики. В работе использовались конфирматорный факторный анализ, описательная статистика, коэффициент альфа Кронбаха, корреляционный анализ, тест Шапиро-Уилкса, t-критерий. Полученный опросник, включающий 48 пунктов (которые предполагают оценку по шкале Ликерта), показал хорошие психометрические свойства. Методика надежно измеряет семь стратегий реагирования на ситуацию изменений, относящихся к двум типам: принятие (1) и непринятие или отвержение перемен (2). Первому типу соответствуют: 1) Освоение изменений, 2) Преодоление трудностей, 3) Стремление к изменениям, 4) Предпочтение неопределенности. Во второй тип входят: 1) Избегание изменений; 2) Упреждение изменений; 3) Сохранение стабильности. При сравнении показателей выраженности стратегий для возрастных групп (17-24 года и 25-67 лет) существенных различий не обнаружено. Это предположительно связано с преобладанием людей молодого возраста в выборке апробации. Анализ половых различий показал, что женщины чаще сообщают о сильных негативных эмоциях, внутреннем сопротивлении в ситуации жизненных перемен. Мужчины чаще указывают на предпочтение неопределенных ситуаций. Новизна методики связана с возможностью операционализировать стратегии реагирования на перемены как изменяющиеся способы взаимодействия с жизненной ситуацией.
\end{abstract}

Ключевые слова: ситуация изменений, принятие-непринятие изменений, стратегия реагирования на ситуацию изменений, восприятие ситуации.

Исследование выполнено при финансовой поддержке РФФИ в рамках научного проекта № 20-013-00838. 


\section{Введение}

Исследования личности в ситуации жизненных изменений представляют один из значимых трендов современной психологии (Асмолов, 2015, 2018; Гришина, 2019). Востребованность этого направления объясняется непрерывностью и постоянством изменений, происходящих в обществе и, как следствие, в жизни человека. На фоне всплеска интереса к данной проблеме одной из важных задач является разработка психологических методик, позволяющих изучать, как человек реагирует на динамично меняющуюся ситуацию в разных сферах жизни.

Проблема изменений является междисциплинарной, большой интерес к ней можно обнаружить в социологии, экономике, менеджменте. При этом в психологии к одной из наиболее разработанных тем относится управление организационными изменениями (Базаров, 2007; Пивовар, 2020). Отметим, что изменения в организации, как правило, проводятся «сверху вниз» - по воле менеджмента компании, т.е. «каскадируются» от организационного уровня до отдельного сотрудника. Данный процесс характеризуется расхождением между скоростью технологических решений и динамикой отношения к инновациям у сотрудников, что порождает их противодействие. На наш взгляд, такие последствия устранимы при учете индивидуально-психологических механизмов принятия изменений, знание которых позволит преодолеть сопротивление через вовлечение и создать условия для «мягкого» внедрения новых технологий. Это связано также с возможностями прогнозирования разных вариантов реагирования, которые определяют непосредственные и отдаленные эффекты перемен.

Для изучения проблемы на индивидуально-психологическом уровне введены понятия и конструкты, описывающие личностные изменения. Так, «личностный динамизм» характеризует «способность и готовность человека изменяться в отсутствие императивной необходимости для этого» (Сапронов, Леонтьев, 2007, с. 68). «Самопреобразование» личности связано с чувством «самотождества» и интеграцией нового знания о себе в структуру Я (Старовойтенко, Щебетенко, 2020). Понятие «самоизменения личности» включает: 1) способность к осознанию «вызовов» ситуации и необходимости изменений; 2) готовность принять эту необходимость и 3) действовать в соответствии с осознаваемыми вызовами. Причем готовность к самоизменениям определяет возможности человека преобразовать свою жизненную ситуацию (Гришина, 2018; Манукян и др., 2020). Более того, по данным недавних исследований, готовность к самоизменениям и связанная с этим гибкость действий и принятия решений позволяют не только конструктивно перестроить свою жизнь в новых условиях, но и принять глобальные перемены (например, в период пандемии) (Битюцкая, 2020а).

Как видно из приведенных определений, одним из значимых компонентов личностных изменений является «готовность». Данное понятие характеризуется как «переход от состояния относительного покоя к состоянию целенаправленной активности, заключающий в себе преемственные формы целеполагания, - трансформащии устремлений индивида с момента зарождения 
активности до момента фактического исполнения задуманного» (Петровский, 2018, с. 331; курсив наш. - Aвт.). Целеполагание субъекта далее связано с такими динамическими характеристиками, как желания, установки, усилия, притязания в единстве с возможностями (Там же). На наш взгляд, так понятая «готовность» позволяет описать фундаментальные механизмы осуществления личностных изменений.

Другим базовым компонентом данного феномена является тип познавательно-исследовательского отношения к миру. При этом, с одной стороны, гибкость познавательной деятельности, готовность к выходу за рамки уже известного определяет отношение к миру как к изменяющемуся и нестабильному. С другой стороны, потребность в определенности, упорядоченности деятельности связана с отношением к миру как к устойчивому и стабильному (Поддьяков, 2001). Интересно отметить, что изменения, рассматриваемые как личностные, часто соотносятся с взаимодействием человека и ситуации (мира). Данный аспект является ключевым при разработке понятия «стиль реагирования на изменения» как предпочитаемого способа адаптации человека, выступающего «промежуточным звеном» между личностью и социальной средой (Базаров, Сычева, 2012).

Подчеркнем также, что наиболее часто используемым в психологии личности является понятие толерантности к неопределенности, которое «имеет непосредственное отношение к описанию процессов личностной саморегуляции в условиях отсутствия устойчивых ориентиров выбора и невозможности применения устоявшихся клише или готовых решений» (Корнилова, Чумакова, 2014, с. 93). Кроме того, неопределенность характеризует двусмысленность, нарушение стереотипов (ambiguity) или неуверенность, неясность будущего (uncertainty). Шкалы, измеряющие толерантность к неопределенности, зачастую рассматривают это качество как стабильную личностную характеристику (Гусев, 2011; Леонтьев и др., 2016; Furnham, Marks, 2013).

Будучи пересекающимися понятиями (Norton, 1975), неопределенность и изменения как психологические конструкты не тождественны друг другу (Битюцкая, Базаров, 2019). В то же время существует большой набор инструментов для измерения толерантности к неопределенности (см. обзоры: Гусев, 2011; Furnham, Marks, 2013), но относительно мало методик для диагностики восприятия и реагирования на ситуацию изменений. Наиболее известные опросники, которые применяются в российской психологии, направлены на диагностику динамизма личности (Сапронов, Леонтьев, 2007), стилей реагирования на изменения (Базаров, Сычева, 2012), психической ригидности (Залевский, 2000) как устойчивых качеств. Данное исследование посвящено разработке и апробации опросника, позволяющего определить восприятие ситуации жизненных изменений, реагирование на нее как динамическую (а не устойчивую) характеристику субъекта.

Целями нашего исследования были: 1) разработка факторной структуры нового опросника «Типы реагирования на ситуацию изменений» (ТРСИ); 2) оценка психометрических свойств и конвергентной валидности шкал ТРСИ. 


\section{Методика}

\section{Участники исследования}

В исследовании по апробации основной (финальной) версии ТРСИ приняли участие 565 человек (в возрасте от 17 до 67 лет; $\mathrm{M}=26.28 ; \mathrm{SD}=8.56$ ), из них 157 мужчин $(\mathrm{M}=25.8 ; \mathrm{SD}=8.62)$ и 408 женщин $(\mathrm{M}=26.47 ; \mathrm{SD}=8.55)$, жители разных регионов России. Более молодую часть выборки (17-24 года) составили студенты вузов - 102 мужчины, 252 женщины; более старшую часть (от 25 лет) специалисты, работающие в различных сферах, - 55 мужчин, 156 женщин.

В бланковой форме (как в очном, так и в заочном вариантах - по электронной почте) опросник предъявлялся 30\% респондентов; остальные заполнили его в онлайн-форме ${ }^{1}$.

\section{Методики исследования}

При проверке основной (финальной) структуры и психометрических свойств ТРСИ использовалась версия, состоящая из 48 пунктов. Респонденту предлагалось описать ситуацию изменений, которая с ним происходила (происходит), и проанализировать пункты опросника по инструкции: «Оцените предложенные ниже утверждения по шкале от 0 до 3 баллов: 0 - реже всего; 1 - редко; 2 - часто; 3 - чаще всего. Если Вы по-разному реагируете на ситуации изменений, соотносите ответ с описанной Вами жизненной ситуацией».

Для оценки конвергентной валидности применялись: опросник «Стили реагирования на изменения» (СРНИ; Базаров, Сычева, 2012), диагностирующий выраженность четырех стилей реагирования на изменения; и шкала толерантности к неопределенности Д. Маклейна MSTAT-II (Multiple Stimulus Types Ambiguity Tolerance-II; Леонтьев и др., 2016).

\section{Процедура анализа данньх}

Для первичной проверки структуры опросника использовался метод главных компонент с вращением Варимакс, а также иерархический кластерный анализ пунктов по методу Варда. Для оценки моделей структуры опросника выполнялся конфирматорный факторный анализ (КФА), проводившийся по методу взвешенных наименьших квадратов с поправками среднего и дисперсии (WLSMV; Muthén, Muthén, 2012), пригодного для анализа порядковых шкал. Расчеты проводились в пакетах SPSS ver.20 и Mplus, ver.8.4.

\footnotetext{
${ }^{1}$ При сравнении показателей шкал для двух форм опросника (в виде бланка и в онлайн-формате) были получены слабые различия или отсутствие различий (на основе сравнения с помощью $t$-критерия и определения величины эффекта $d$ Коэна). Также мы получили схожие показатели оценки финальной версии модели при ее проверке на двух подвыборках (респондентов, заполнявших опросник в бланковой и онлайн-формах). В связи с этим мы анализировали результаты совместно.
} 
Для проверки шкал опросника использовались: коэффициент $\alpha$ Кронбаха, корреляционный анализ (коэффициент Пирсона). При сравнении показателей между группами применялся $t$-критерий Стьюдента для несвязанных выборок, величина статистического эффекта оценивалась с помощью $d$ Коэна.

\section{Первичная версия ТРСИ}

Для четырех стилей реагирования на изменения: реализующего, инновационного, реактивного, консервативного (Базаров, Сычева, 2012) были описаны особенности восприятия перемен, связанных с «поворотными» жизненными событиями (Битюцкая, Базаров, 2019). Изначально мы предположили, что можно выделить четыре одноименных типа реагирования на ситуацию изменений. Для каждого такого типа восприятия были разработаны пункты опросника².

Первичная версия ТРСИ включала 100 пунктов. При разработке опросника пункты группировались в смысловые блоки: реакции в стабильных и быстро меняющихся условиях, способы адаптации к ситуации перемен; планирование и реализация плана; отношение к возможностям и ограничениям, к неудаче и успеху, к правилам в ситуации изменений; эмоции и прогнозы, восприятие будущего; отношения с людьми и др. Для каждого типа восприятия были сформулированы утверждения, соответствующие смысловым блокам. В ряде случаев мы создавали пары противоположных по смыслу утверждений. Кроме того, чтобы впоследствии отобрать наиболее «хорошо работающие» формулировки, часть созданных утверждений дублировались по смыслу.

Для улучшения формулировок пунктов, а также проверки их смыслового соответствия четырем стилям проводились индивидуальные и групповые обсуждения с экспертами (всего 36 человек - 4 квалифицированных психолога, а также студенты и магистранты, обучающиеся по специальностям «Психология» и «Журналистика»).

Апробация первичной версии опросника была проведена на выборке взрослых респондентов (в возрасте от 18 до 48 лет; $\mathrm{n}=488$ ) (Базаров, Битюцкая, 2020). При этом было выделено пять факторов: большинство пунктов сгруппировались в четыре ожидаемых фактора, соответствующих типам реагирования. Кроме того, пункты об отношениях с людьми образовали пятый фактор (например: «Мне важно сохранять длительные стабильные отношения с другими людьми»; «Я с легкостью разрываю отношения с другими людьми»).

\section{Разработка и проверка факторной структуры ТРСИ}

Уточнение состава шкал опросника выполнялось в несколько этапов. Кратко опишем их, а затем подробно рассмотрим финальную модель.

\footnotetext{
${ }^{2}$ Пункты опросника разработаны и первично апробированы совместно с А.А. Червонным, в рамках дипломного проекта под руководством одного из авторов: Червонный А.А. (2019). Особенности переживания жизненных событий при разных стилях реагирования на ситуацию изменений [Выпускная квалификационная работа специалиста по психологии, МГУ имени М.В. Ломоносова].
} 
На первом этапе анализа мы включили в модель 86 пунктов (I модель), которые на основании теоретических представлений, первичного корреляционного анализа и ЭФА были отнесены к пяти факторам-шкалам: реализующий, инновационный, реактивный, консервативный (четыре предполагаемых типа) и отношения с людьми в ситуации изменений. Кроме того, мы проверяли четырехфакторную II модель (77 пунктов), исключающую утверждения об отношениях с людьми. Оценки обеих моделей оказались близки к общепринятым критериям, но не могут считаться удовлетворительными (см. таблицу 1, строки I и II), поэтому были предприняты дальнейшее сокращение вопросов и пересмотр состава шкал.

На втором этапе была оценена III модель опросника. В нее вошло меньшее число пунктов - 66 (были отсеяны утверждения, коррелирующие с несколькими факторами, а также имеющие сильную асимметрию распределения ответов). Кроме того, анализ корреляций обнаружил связь некоторых пунктов, описывающих положительную оценку ситуации изменений. Поскольку позитивная оценка является важным фактором принятия изменений, мы проверили структуру ТРСИ с выделением такой шкалы, включив в нее утверждения из шкал инновационного и реализующего типов, например: «Я нахожу что-нибудь позитивное в любой новой ситуации»; «Изменения позволяют мне творчески мыслить». Однако оценки III модели оказались недостаточно высокими (см. таблицу 1).

На третьем этапе для оптимизации структуры опросника был проведен дополнительный содержательный анализ в опоре на показатели КФА, полученные на предыдущих этапах. В результате число пунктов было сокращено до 48. Сокращенные модели включали в себя 5 шкал: реализующий, инновационный, реактивный, консервативный типы и позитивная оценка ( $\mathrm{V}$ модель $)$ - и 4 шкалы типов ( $V$ модель). Однако результаты КФА также не позволили считать полученные модели вполне соответствующими данным (см. таблицу 1).

Поскольку оценки всех описанных моделей оказались недостаточно высокими, на четвертом этапе мы провели кластерный анализ пунктов, который показал, что может быть выделено 7 групп утверждений. При этом пункты, которые ранее относились к положительной оценке изменений, распределились в шкалы инновационного и реализующего типов (в соответствии с нашими первоначальными предположениями). Пункты трех шкал, которые на первом этапе, в соответствии с гипотезой о четырех типах, группировались в единые шкалы (реализующий, инновационный, консервативный типы), разделились на 2 шкалы каждая. Таким образом, мы получили VI модель, состоящую из 7 шкал, которые содержательно соответствуют следующим типам: реализующий-1, реализующий-2, инновационный-1, инновационный2, реактивный, консервативный-1, консервативный-2. Проверка этой финальной модели опросника с помощью КФА показала хорошие оценки качества: $\mathrm{RMSEA}=0.047, \mathrm{CFI}=0.921, \chi^{2}(1059)=2407$. Для сравнения показатели шести проверенных моделей приведены в таблице 2. 
Таблица 1

Показатели соответствия проверенных моделей данным (КФА)

\begin{tabular}{|l|l|c|c|c|c|c|}
\hline \multirow{2}{*}{ Модель } & \multirow{2}{*}{ Количество шкал } & \multirow{2}{*}{$\begin{array}{c}\text { Количество } \\
\text { пунктов }\end{array}$} & \multicolumn{4}{|c|}{ Показатели соответствия модели данным } \\
\cline { 5 - 8 } & & RMSEA & CFI & TLI & $\chi^{2}$ \\
\hline I & $\begin{array}{l}5 \text { (4 типа и отноше- } \\
\text { ния с людьми) }\end{array}$ & 86 & 0.099 & 0.873 & 0.869 & $\chi^{2}(3559)=23222$ \\
\hline II & $\begin{array}{l}\text { (4 типа) } \\
\text { (4 (4 типа и положи- } \\
\text { тельная оценка) }\end{array}$ & 66 & 0.101 & 0.904 & 0.901 & $\chi^{2}(2069)=14017$ \\
\hline IV & $\begin{array}{l}5 \text { (4 типа и положи- } \\
\text { тельная оценка) }\end{array}$ & 48 & 0.062 & 0.861 & 0.854 & $\chi^{2}(1121)=3549$ \\
\hline V & 4 (4 типа) & 48 & 0.097 & 0.920 & 0.916 & $\chi^{2}(1027)=5734$ \\
\hline $\begin{array}{l}\text { VI } \\
\text { финальная }\end{array}$ & 7 шкал & 48 & 0.047 & 0.921 & 0.915 & $\chi^{2}(1059)=2407$ \\
\hline
\end{tabular}

Полученная структура представляется хорошо интерпретируемой и удачно описывающей феномен реагирования на ситуацию изменений. Выделенные факторы-шкалы можно признать соответствующими стратегиям реагирования на ситуацию изменений. Они обозначены следующим образом:

1) Реализующий-1 - Освоение изменений;

2) Реализующий-2 - Преодоление трудностей;

3) Инновационный-1 - Стремление к изменениям;

4) Инновационный-2 - Предпочтение неопределенности;

5) Реактивный - Избегание изменений;

6) Консервативный-1 - Упреждение изменений;

7) Консервативный-2 - Сохранение стабильности.

Состав факторов, стандартизированные факторные нагрузки пунктов в финальной модели и показатели надежности-согласованности (коэффициент ж Кронбаха) факторов-шкал ТРСИ приведены в таблице 2.

Как видно из таблицы 2, все факторные нагрузки в финальной модели достаточно высокие (значимость отличия от нуля $p<0.001$ во всех случаях). Показатели надежности-согласованности оказались высокими для всех семи шкал.

Между факторами в структурной модели наблюдаются достаточно высокие корреляции. Как и ожидалось, между факторами, указывающими на принятие ситуации изменений (Освоение изменений, Преодоление трудностей, Стремление к изменениям и Предпочтение неопределенности), они положительные - от 0.621 до 0.881, так же как и между факторами непринятия изменений (Избегание изменений, Упреждение изменений и Сохранение стабильноcmu) (от 0.740 до 0.785). Между факторами этих двух групп наблюдаются отрицательные корреляции (от -0.358 до -0.702$)$. В таблице 3 представлены корреляции шкал. 
Таблица 2

Состав факторов, стандартизированные факторные нагрузки пунктов в конфирматорной модели и показатели надежности-согласованности

\begin{tabular}{|c|c|c|}
\hline \begin{tabular}{|c|} 
№ \\
пункта
\end{tabular} & Факторы и входящие в их состав пункты & $\begin{array}{c}\text { Факторные } \\
\text { нагрузки }\end{array}$ \\
\hline \multicolumn{3}{|c|}{ Освоение изменений (5 п.), $\alpha=0.717$} \\
\hline 1 & В ситуации изменений я испытываю позитивные эмоции & 0.622 \\
\hline 3 & В ситуации изменений я уверен в предстоящем успехе & 0.683 \\
\hline 7 & $\begin{array}{l}\text { Ограничения в ситуации изменений - это преграда, которую можно } \\
\text { легко преодолеть }\end{array}$ & 0.543 \\
\hline 26 & Мне легко перестроить свою деятельность в новых условиях & 0.684 \\
\hline 30 & $\begin{array}{l}\text { Чтобы приспособиться к изменяющейся обстановке, я быстро и } \\
\text { активно действую }\end{array}$ & 0.621 \\
\hline \multicolumn{3}{|c|}{ Преодоление трудностей (10 п.), $\alpha=0.861$} \\
\hline 12 & $\begin{array}{l}\text { Даже если ситуация развивается неудачно, я все равно извлекаю из } \\
\text { нее пользу }\end{array}$ & 0.614 \\
\hline 17 & $\begin{array}{l}\text { Я оцениваю ситуацию изменений оптимистично, если предстоит } \\
\text { достижение значимой цели }\end{array}$ & 0.729 \\
\hline 20 & $\begin{array}{l}\text { Новая ситуация содержит в себе выгоды и преимущества, нужно } \\
\text { лишь подстроить ее под себя }\end{array}$ & 0.617 \\
\hline 21 & В ситуации изменений я продумываю позитивные варианты ее развития & 0.643 \\
\hline 25 & $\begin{array}{l}\text { Даже если ситуация изменений развернулась не в мою пользу, я } \\
\text { 3наю, что в будущем смогу победить }\end{array}$ & 0.780 \\
\hline 28 & $\begin{array}{l}\text { Если новая ситуация связана с ограничениями, я найду способ изме- } \\
\text { нить ее к лучшему }\end{array}$ & 0.752 \\
\hline 31 & Я нахожу что-нибудь позитивное в любой новой ситуации & 0.763 \\
\hline 35 & $\begin{array}{l}\text { В ситуации изменений я нахожу возможности для реализации своих } \\
\text { идей }\end{array}$ & 0.684 \\
\hline 40 & Если что-то идет не так, я гибко меняю свой план действий & 0.580 \\
\hline 45 & $\begin{array}{l}\text { В ситуации неопределенности я точно знаю, что найду пути решения } \\
\text { трудной задачи }\end{array}$ & 0.729 \\
\hline \multicolumn{3}{|c|}{ Стремление к изменениям (8 п.), $\alpha=0.838$} \\
\hline 5 & $\begin{array}{l}\text { Мне нужно, чтобы в жизни происходили изменения, иначе она } \\
\text { кажется серой и скучной }\end{array}$ & 0.638 \\
\hline 14 & Изменения для меня настолько важны, что я сам их создаю & 0.663 \\
\hline 16 & $\begin{array}{l}\text { Для меня изменения в жизни - это стимул, который побуждает к } \\
\text { действию }\end{array}$ & 0.730 \\
\hline 37 & В ситуации изменений я чувствую прилив сил & 0.789 \\
\hline 39 & Я воспринимаю изменения как возможность самореализации & 0.754 \\
\hline 42 & $\begin{array}{l}\text { Изменения, которые должны произойти в будущем, мне представ- } \\
\text { ляются желательными }\end{array}$ & 0.592 \\
\hline 44 & Изменения позволяют мне творчески мыслить & 0.684 \\
\hline 48 & Ситуация изменений побуждает меня к поиску новых решений & 0.711 \\
\hline
\end{tabular}


Таблица 2 (окончание)

\begin{tabular}{|c|c|c|}
\hline \multicolumn{3}{|c|}{ Предпочтение неопределенности (4 п.), $\alpha=0.718$} \\
\hline 9 & Я предпочитаю действовать не по плану, а импровизировать & 0.589 \\
\hline 23 & Меня привлекают ситуации без заданных ориентиров и правил & 0.567 \\
\hline 33 & Мне нравится неопределенность ситуации изменений & 0.708 \\
\hline 47 & В быстро меняющейся ситуации я чувствую себя как рыба в воде & 0.824 \\
\hline \multicolumn{3}{|c|}{ Избегание изменений (10 пунктов), $\alpha=0.865$} \\
\hline 2 & Я болезненно реагирую на жизненные изменения & 0.729 \\
\hline 4 & Даже если перемены к лучшему, я сопротивляюсь им & 0.537 \\
\hline 6 & $\begin{array}{l}\text { В ситуации изменений я тяжело переношу нарушение устоявшегося } \\
\text { образа жизни }\end{array}$ & 0.713 \\
\hline 10 & Неопределенность ситуации изменений меня тревожит & 0.716 \\
\hline 11 & В ситуации изменений я быстро истощаюсь & 0.591 \\
\hline 15 & В ситуации изменений я испытываю негативные эмоции & 0.759 \\
\hline 24 & $\begin{array}{l}\text { В ситуации изменений у меня уходит много времени и сил на то, } \\
\text { чтобы совладать с отрицательными эмоциями }\end{array}$ & 0.635 \\
\hline 29 & $\begin{array}{l}\text { Если в моей жизни происходят изменения, мне нужно много време- } \\
\text { ни, чтобы их принять }\end{array}$ & 0.763 \\
\hline 38 & $\begin{array}{l}\text { Отсутствие установленных правил в ситуации изменений вызывает } \\
\text { у меня ощущение потерянности }\end{array}$ & 0.727 \\
\hline 43 & Я долго восстанавливаюсь после динамичной ситуации & 0.603 \\
\hline \multicolumn{3}{|c|}{ Упреждение изменений (5 п.), $\alpha=0.746$} \\
\hline 8 & Думая о развитии ситуации изменений, я опасаюсь неприятностей & 0.575 \\
\hline 18 & В ситуации изменений я в первую очередь замечаю препятствия & 0.690 \\
\hline 27 & $\begin{array}{l}\text { В ситуации изменений я особенно тщательно продумываю негатив- } \\
\text { ные варианты развития событий }\end{array}$ & 0.587 \\
\hline 34 & $\begin{array}{l}\text { Я думаю, что новая ситуация скорее принесет отрицательные } \\
\text { последствия }\end{array}$ & 0.735 \\
\hline 36 & Незапланированные события вызывают у меня негативные эмоции & 0.735 \\
\hline \multicolumn{3}{|c|}{ Сохранение стабильности (6 п.), $\alpha=0.719$} \\
\hline 13 & Я предпочитаю жить в устоявшихся, предсказуемых условиях & 0.634 \\
\hline 19 & $\begin{array}{l}\text { Прогнозируя будущее, я беспокоюсь о том, хватит ли мне сил на } \\
\text { решение сложной задачи }\end{array}$ & 0.725 \\
\hline 22 & Я делаю все, чтобы сохранить стабильность обстановки & 0.484 \\
\hline 32 & $\begin{array}{l}\text { В изменяющихся условиях я упорно пытаюсь применить известный } \\
\text { алгоритм действий }\end{array}$ & 0.488 \\
\hline 41 & $\begin{array}{l}\text { Я положительно оцениваю возможности, только если могу встроить } \\
\text { их в существующий план }\end{array}$ & 0.600 \\
\hline 46 & Я с трудом вношу изменения в разработанный план & 0.672 \\
\hline
\end{tabular}


Таблица 3

Корреляции ( $r$ Пирсона) между показателями шкал $(\mathrm{n}=565)$

\begin{tabular}{|l|c|c|c|c|c|c|}
\hline \multicolumn{1}{|c|}{ Шкалы } & Преодоление & Стремление & Предпочтение & Избегание & Упреждение & Сохранение \\
\hline Освоение & $0.691^{*}$ & $0.628^{*}$ & $0.518^{*}$ & $-0.543^{*}$ & $-0.466^{*}$ & $-0.314^{*}$ \\
\hline Преодоление & 1 & $0.669^{*}$ & $0.475^{*}$ & $-0.394^{*}$ & $-0.455^{*}$ & $-0.272^{*}$ \\
\hline Стремление & & 1 & $0.529^{*}$ & $-0.330^{*}$ & $-0.414^{*}$ & $-0.335^{*}$ \\
\hline Предпочтение & & & 1 & $-0.397^{*}$ & $-0.332^{*}$ & $-0.440^{*}$ \\
\hline Избегание & & & & 1 & $0.622^{*}$ & $0.579^{*}$ \\
\hline Упреждение & & & & & 1 & $0.573^{*}$ \\
\hline
\end{tabular}

$* p<0.001$.

Представленные корреляции достаточно предсказуемы: наибольшие положительные значения получены между показателями шкал Освоение изменений и Преодоление трудностей. Также сильные положительные корреляции наблюдаются между этими двумя шкалами и Стремлением к изменениям. Сильные положительные корреляции получены между факторами Избегания, Упреждения изменений и Сохранения стабильности. В целом можно выделить две группы взаимосвязанных факторов: первая из них описывает принятие ситуации изменений, вторая - непринятие (отвержение) перемен. Шкалы, относящиеся к этим группам, отрицательно коррелируют между собой.

Эти результаты указывают на возможность выделения двух факторов более высокого уровня. Для оценки этой идеи мы проверили дополнительную модель, соответствующую финальной, но включающую два фактора второго уровня: Принятие изменений (в него вошли Освоение изменений, Преодоление трудностей, Стремление к изменениям и Предпочтение неопределенности) и Непринятие изменений (Избегание изменений, Упреждение изменений и Сохранение стабильности). Оценки качества остались достаточно высокими $\left(\mathrm{RMSEA}=0.051, \mathrm{CFI}=0.907, \chi^{2}(1072)=2647\right)$. При этом нагрузки факторов второго порядка на факторы, соответствующие шкалам опросника, были высокими (стандартизованные значения выше 0.8 во всех случаях), а корреляция между этими факторами оценивалась на уровне -0.657 .

В итоге мы получили структуру опросника ТРСИ, состоящую из семи шкал, измеряющих выраженность стратегий реагирования на ситуацию изменений и соотносимых с двумя типами.

\section{Tuп I. Принятие изменений}

1. Освоение изменений определяет быструю адаптацию к переменам, позитивные эмоции и способность легко перестроить деятельность в новых условиях.

2. Преодоление трудностей включает уверенность в успешном разрешении проблемных ситуаций и стремление извлечь пользу даже в случае неудачного 
развития событий; анализ решения, гибкое планирование, ориентированность на достижение цели.

3. Стремление к изменениям описывает высокую значимость и потребность в переменах, привлекательность ситуации изменений, интерес к новизне.

4. Предпочтение неопределенности предполагает толерантность к неопределенности, удовольствие от быстрой смены событий, способность к импровизации.

\section{Tuп II. Непринятие изменений}

5. Избегание изменений описывает сильные негативные эмоции в ситуации перемен (тревогу, страх, панику); внутреннее сопротивление; ощущение потери сил и ресурсов.

6. Упреждение изменений характеризует негативное отношение к переменам, связанное с отрицательными прогнозами, фокусированием на препятствиях. В целом это направлено на предотвращение изменений.

7. Сохранение стабильности предполагает стремление сохранить (вернуть) стабильность ситуации в процессе изменений, попытки применения ранее разработанных алгоритмов действий в новых условиях, тщательное планирование жизненных событий.

\section{Возрастные и половые различия выраженности стратегий реагирования на изменения}

Показатели выраженности стратегий реагирования на изменения для двух возрастных групп (младше и старше 25 лет), а также результаты сравнения средних значений и величина статистического эффекта ( $d$ Коэна) приведены в таблице 4.

Как видно из таблицы 4, различия между двумя возрастными группами значимы только по шкале Освоение изменений: в старшей группе среднее значение по этой шкале несколько выше, однако статистический эффект слабый.

Результаты сравнения показателей по шкалам для групп мужчин и женщин даны в таблице 5.

Различия между мужчинами и женщинами наиболее существенны по шкале Избегание изменений, эффект в данном случае оказался большим, средний балл выше у женщин. Также значимы различия по шкалам Предпочтение неопределенности (величина эффекта средняя, средний балл выше у мужчин); Сохранение стабильности (величина эффекта небольшая, средний балл выше у женщин) и Освоение изменений (величина эффекта небольшая, средний балл выше у мужчин).

\section{Конвергентная валидность}

В таблице 6 представлены корреляции между показателями шкал ТРСИ и методик сравнения: СРНИ и MSTAT-II. Эти результаты достаточно ожидаемы: 
Таблица 4

Сравнение показателей шкал ТРСИ в двух возрастных группах

\begin{tabular}{|l|c|c|l|c|}
\hline \multicolumn{1}{|c|}{ Шкалы } & $\begin{array}{c}\text { Среднее значение } \\
\text { в группе младше } \\
\text { 25 лет* }\end{array}$ & $\begin{array}{c}\text { Среднее значение } \\
\text { в группе 25 лет и } \\
\text { старше }\end{array}$ & \multicolumn{1}{|c|}{ Статистика $\boldsymbol{t}$-критерия } & $\boldsymbol{d}$ Коэна \\
\hline Освоение & $1.73(0.55)$ & $1.83(0.48)$ & $\mathrm{t}(487)=-2.329 ; \mathrm{p}=0.020$ & 0.196 \\
\hline Преодоление & $2.09(0.50)$ & $2.13(0.44)$ & $\mathrm{t}(484)=-0.968 ; \mathrm{p}=0.334$ & 0.082 \\
\hline Стремление & $2.01(0.53)$ & $2.02(0.49)$ & $\mathrm{t}(467)=-0.147 ; \mathrm{p}=0.883$ & 0.013 \\
\hline Предпочтение & $1.28(0.60)$ & $1.33(0.58)$ & $\mathrm{t}(458)=-1.007 ; \mathrm{p}=0.314$ & 0.087 \\
\hline Избегание & $1.38(0.58)$ & $1.31(0.48)$ & $\mathrm{t}(509)=1.582 ; \mathrm{p}=0.114$ & -0.131 \\
\hline Упреждение & $1.36(0.60)$ & $1.39(0.52)$ & $\mathrm{t}(492)=-0.610 ; \mathrm{p}=0.542$ & 0.051 \\
\hline Сохранение & $1.64(0.51)$ & $1.60(0.45)$ & $\mathrm{t}(488)=0.903 ; \mathrm{p}=0.367$ & -0.076 \\
\hline
\end{tabular}

Таблица 5

Сравнение показателей шкал ТРСИ в группах мужчин и женщин

\begin{tabular}{|l|c|c|c|c|}
\hline \multicolumn{1}{|c|}{ Шкалы } & $\begin{array}{c}\text { Среднее значение } \\
\text { в группе мужчин* }\end{array}$ & $\begin{array}{l}\text { Среднее значение } \\
\text { в группе женщин }\end{array}$ & Статистика $\boldsymbol{t}$-критерия & $\boldsymbol{d}$ Коэна \\
\hline Освоение & $1.84(0.52)$ & $1.74(0.53)$ & $\mathrm{t}(288)=2.139, \mathrm{p}=0.033$ & -0.200 \\
\hline Преодоление & $2.13(0.45)$ & $2.10(0.48)$ & $\mathrm{t}(301)=0.642, \mathrm{p}=0.521$ & -0.059 \\
\hline Стремление & $1.96(0.49)$ & $2.03(0.52)$ & $\mathrm{t}(297)=-1.527, \mathrm{p}=0.128$ & 0.140 \\
\hline Предпочтение & $1.47(0.62)$ & $1.23(0.57)$ & $\mathrm{t}(265)=4.187, \mathrm{p}<0.001$ & -0.408 \\
\hline Избегание & $1.09(0.48)$ & $1.46(0.53)$ & $\mathrm{t}(313)=-7.992, \mathrm{p}<0.001$ & 0.716 \\
\hline Упреждение & $1.36(0.53)$ & $1.38(0.58)$ & $\mathrm{t}(308)=-0.360, \mathrm{p}=0.719$ & 0.033 \\
\hline Сохранение & $1.55(0.48)$ & $1.66(0.49)$ & $\mathrm{t}(288)=-2.453, \mathrm{p}=0.015$ & 0.229 \\
\hline
\end{tabular}

* В скобках указано стандартное отклонение.

три шкалы непринятия ситуации изменений положительно связаны с реактивным и консервативным стилями (описывающими ориентацию на стабильность) и отрицательно - с реализующим, инновационным стилями (характеризующими ориентацию на инновационность), а также с толерантностью к неопределенности. Для четырех шкал принятия ситуации изменений наблюдается обратная картина. Эти шкалы отрицательно коррелируют с реактивным и консервативным стилями; положительно - с реализующим, инновационным стилями и толерантностью к неопределенности.

\section{Обсуждение результатов}

Для определения факторной структуры нового опросника на разных этапах было проверено шесть моделей, включающих от 86 до 48 пунктов и 4, 5, 7 
Таблица 6

Корреляции ( $r$ Пирсона) между показателями шкал ТРСИ и методик сравнения: СРНИ (n = 194) и MSTAT-II $(\mathrm{n}=163)$

\begin{tabular}{|l|c|c|c|c|c|}
\hline \multirow{2}{*}{ шкалы } & \multicolumn{5}{|c|}{ Стили реагирования на изменения } \\
\cline { 2 - 6 } & Реализующий & $\begin{array}{c}\text { Инновацион- } \\
\text { ный }\end{array}$ & Реактивный & $\begin{array}{c}\text { Консерватив- } \\
\text { ный }\end{array}$ & $\begin{array}{c}\text { Толерантность } \\
\text { к неопределен- } \\
\text { ности }\end{array}$ \\
\hline Освоение & 0.479 & 0.257 & -0.473 & -0.262 & 0.473 \\
\hline Преодоление & 0.588 & 0.364 & -0.573 & -0.373 & 0.502 \\
\hline Стремление & 0.507 & 0.456 & -0.494 & -0.459 & 0.588 \\
\hline Предпочтение & 0.514 & 0.606 & -0.511 & -0.606 & 0.516 \\
\hline Избегание & -0.462 & -0.211 & 0.464 & 0.211 & -0.657 \\
\hline Упреждение & -0.487 & -0.236 & 0.483 & 0.234 & -0.468 \\
\hline Сохранение & -0.496 & -0.464 & 0.493 & 0.466 & -0.645 \\
\hline
\end{tabular}

Примечание. Коэффициенты корреляции значимо отличаются от нуля на уровне $p \leqslant 0.001$.

факторов. Полученные оценки моделей позволили установить, что семифакторное решение наиболее соответствует эмпирическим данным. Таким образом, оптимальной является структура ТРСИ, в которой три шкалы (из четырех изначально предполагаемых) разделились на две. Например, утверждения, разработанные для предполагаемого инновационного типа, разделены на две шкалы, связанные с предпочтением неопределенности (1) и стремлением создавать перемены (2). Мы полагаем, что семишкальный опросник позволит более дифференцированно изучать реагирование на ситуацию изменений.

Анализ корреляций между показателями шкал и связей шкал с внешними методиками, а также показатели иерархической факторной модели позволяют говорить о наличии двух типов, описывающих принятие и непринятие изменений. Принятие включает стратегии: Освоение изменений, Преодоление трудностей, Стремление к изменениям, Предпочтение неопределенности. Непринятие предполагает Избегание изменений, их Упреждение, Сохранение стабильности. Выделение двух типов согласуется с представлениями о базовых типах познавательно-исследовательского отношения к миру (Поддьяков, 2001).

На выборке апробации опросника данный вывод (о наличии двух крупных типов) выглядит обоснованно. В то же время в индивидуальных профилях испытуемых зачастую встречаются двойственные (амбивалентные) формы реагирования, при которых высоко выражены как отдельные стратегии принятия, так и непринятия изменений.

Понятие «стратегия» как характеристика способа реагирования применяется потому, что позволяет описать направленность восприятия и деятельности в ситуации изменений. Эта направленность может меняться в зависимости от целей и задач человека в конкретной ситуации («трансформация устремлений», по В.А. Петровскому, 2018). Такая интерпретация (стратегии) 
соотносима с категорией «копинг-стратегия», если понимать это как способ взаимодействия с ситуацией изменений или ее избегания (Битюцкая, 2020б).

Нам важно ответить на вопрос, почему при разработке финальной версии структуры опросника оказались отсеяны больше половины пунктов. Отметим, что это было запланированным шагом: пункты для первичной версии методики создавались с избытком (вводились пары противоположных по значению пунктов и дублирующие утверждения), чтобы выбрать более надежные по психометрическим показателям утверждения.

Пункты, описывающие отношения с людьми в ситуации изменений, удалены, так как однозначно не связаны с типами, образуя отдельный фактор. Это ожидаемый результат, на основе анализа качественных данных нами было показано отсутствие единых способов взаимодействия с другими людьми для стилей реагирования на изменения (Битюцкая, Базаров, 2019). По результатам проведенного анализа мы сочли, что выделение такой шкалы не согласуется с концептом опросника: она не сочетается с выделенными типами, а образует отдельное измерение.

При сравнении возрастных групп мы не получили заметных отличий, при этом в обеих группах сильно выражена стратегия принятия изменений и относительно слабо - стратегии непринятия изменений. Вероятно, это связано с тем, что 84\% нашей выборки - люди 17-35 лет. Увеличения консервативных тенденций непринятия перемен можно ожидать в более старшем возрасте. Однако это требует отдельного исследования.

Анализ половых различий указывает на то, что женщины чаще, чем мужчины, сообщают о сильных негативных эмоциях, внутреннем сопротивлении в ситуации перемен. Результаты, связанные с большей эмоциональностью женщин (или их представлениями о себе как эмоциональных), сопоставимы с данными, описывающими особенности копинг-стратегий. На европейских и американских выборках показано, что женщины более склонны к эмоционально-ориентированному копингу, а мужчины чаще используют самоконтроль (Битюцкая, 2015, с. 42, 43; Рассказова и др., 2013). Корреляция тревоги, неуверенности женщин с избеганием и эмоционально-ориентированным реагированием описана относительно супружеского копинга в ситуации жизненных изменений при рождении второго ребенка (Крюкова, 2014). Кроме того, подтверждается вывод о том, что исследования, основанные на самоотчетах, описывают женщин как более тревожных (Кон, 2009, с. 196). Также оказались значимы различия мужчин и женщин в Предпочтении неопределенности: мужчины чаще сообщают о желании действовать в ситуации без заданных правил и ориентиров, удовольствии от быстрой смены событий, способности к импровизации. Этот результат согласуется с данными о «гендерной разнице в степени принятия риска», связанной с влечением к острым ощущениям, стремлением к новизне, к освоению нового и необычного как характеристиками мужского поведения (Кон, 2009).

Поскольку при разработке концептуальных предположений о ТРСИ использовалась идея четырех стилей реагирования на изменения, операционализируемых с помощью опросника СРНИ, представляется важным сравнение 
двух методик. Отметим, что допущение четырех стилей является теоретическим построением; выделение стилей проводилось с учетом двух оснований: 1) ориентация на инновационность/стабильность, 2) ориентация на суждение/восприятие (Базаров, Сычева, 2012). В нашей работе, направленной на определение типов ситуационного реагирования, подтвердилось лишь первое основание, которое схоже с принятием/непринятием изменений.

Концептуальное отличие этих двух опросников состоит в том, что ТРСИ методика ситуационного типа, т.е. описывает анализ опыта переживания ситуации изменений, происходившей в жизни респондента (или актуальной для него). Для СРНИ же важна идея стиля как устойчивой характеристики личности и предпочитаемого варианта реагирования в разных ситуациях. Содержательное различие методик состоит в том, что для ТРСИ специально разработаны оригинальные утверждения на основе эмпирических данных качественного исследования (Битюцкая, Базаров, 2019) и получена новая структура опросника. При этом шкалы нового опросника продемонстрировали ожидаемые связи с показателями СРНИ.

Возможность операционализировать именно стратегии как способы взаимодействия с ситуацией изменений составляет новизну методики, поскольку многие существующие опросники предназначены для измерения более устойчивых форм отношения к условиям неопределенности и изменений (толерантность к неопределенности, личностный динамизм, стили реагирования на изменения). Концептуально данный опросник более схож с методиками ситуационной направленности. Примером такой методики является ситуационный опросник «Типы ориентаций в трудной ситуации», предназначенный для диагностики факторов восприятия трудности (Битюцкая, Корнеев, 2020).

\section{Заключение}

Полученный опросник позволяет описать и надежно измерить семь стратегий реагирования на ситуацию изменений, относящихся к двум типам: принятие (1) и непринятие (2) перемен. К первому типу относятся четыре стратегии, которые описывают направленность на 1) активное освоение изменений; 2) преодоление трудностей; 3) стремление к изменениям; 4) предпочтение неопределенности. Во второй тип входят три стратегии, которые предполагают направленность на 1) избегание изменений; 2) упреждение (предотвращение) изменений; 3) сохранение стабильности.

Проверена конвергентная валидность опросника ТРСИ. Шкалы, характеризующие принятие и непринятие изменений, ожидаемо коррелируют с выраженностью соответствующих шкал методик, направленных на оценку стилей реагирования на изменения и толерантности к неопределенности.

В отличие от других опросников, диагностирующих реагирование на изменения и толерантность к неопределенности как устойчивые личностные качества, ТРСИ является методикой ситуационного типа. Данный опросник предназначен для измерения параметров восприятия и способов взаимодействия с 
ситуацией изменений, выраженность которых у субъекта может меняться в зависимости от его целей в конкретной ситуации, а также ее переосмысления.

Основанный на рефлексии человеком своей позиции относительно ситуации изменений, опросник ТРСИ имеет потенциал применения не только в исследовательских, но и в практических целях. Он может использоваться в процессе психологического сопровождения человека, переживающего перемены как трудную жизненную ситуацию.

\section{Литература}

Асмолов, А. Г. (2015). Психология современности: вызовы неопределенности, сложности и разнообразия. Психологические исследования: электронный научный журнал, 8(40), 1. http://psystudy.ru/num/2015v8n40/1109-asmolov40

Асмолов, А. Г. (ред.). (2018). Mobilis in тоbili: личность в эпоху перемен. М.: ИД ЯСК.

Базаров, Т. Ю. (2007). Психологические грани изменяющейся организации. М.: Аспект пресс.

Базаров, Т. Ю., Битюцкая, Е. В. (2020). Разработка нового опросника Типы реагирования на ситуацию изменений (ТРСИ). В кн. Ананьевские чтения - 2020. Психология служебной деятельности: достижения и перспективы развития (в честь 75-летия Победы в Великой Отечественной войне 1941-1945 г2.): Материаль Международной научной конференции (с. 619-620). СПб.: Скифия-принт.

Базаров, Т. Ю., Сычева, М. П. (2012). Создание и апробация опросника «Стили реагирования на изменения». Психологические исследования: электронный научный журнал, 5(25), 12. http://psystudy.ru/index.php/num/2012v5n25/724-bazarov25.html

Битюцкая, Е. В. (2015). Опросник способов копинга: методическое пособие. М.: ИИУ МГОУ.

Битюцкая, Е. В. (2020а). Смысл угрозы и угроза смыслу: моделирование восприятия ситуации пандемии COVID-19. Вестник Московского государственного областного университета. Серия Психологические науки, 4, 21-39. https://doi.org/10.18384/2310-7235-2020-4-21-39

Битюцкая, Е. В. (2020б). Человек и ситуация неопределенности: стратегии взаимодействия. В кн. Е. С. Асмаковец (отв. ред.), Личность профессионала: развитие, образование, здоровъе: Сборник научных статей. Омск. Кельце. Пловдив (вып. 5, с. 44-50). Омск: Издательский центр КАН.

Битюцкая, Е. В., Базаров, Т. Ю. (2019). Особенности восприятия жизненных событий людьми с разными предпочитаемыми стилями реагирования на изменения. Вопросы психологии, 3, 94-106.

Битюцкая, Е. В., Корнеев, А. А. (2020). Диагностика восприятия жизненных трудностей: ситуационный опросник «Типы ориентаций в трудной ситуации». Вестник Московского государственного областного университета (электронный журнал), 4, 141-163. http://doi.org/10.18384/2224-0209-2020-4-1047

Гришина, Н. В. (2018). «Самоизменения» личности: возможное и необходимое. Вестник СанктПетербургского университета. Психология и педагогика, 8(2), 126-138. https://doi.org/10.21638/11701/spbu16.2018.202

Гришина, Н. В. (ред.). (2019). Психология личности: Пребывание в изменении. СПб.: Изд-во Санкт-Петербургского университета.

Гусев, А. И. (2011). Толерантность к неопределенности как составляющая личностного потенциала. В кн. Д. А. Леонтьев (ред.), Личностный потеницал: структура и диагностика (с. 300-329). М.: Смысл. 
Залевский, Г. В. (2000). Томский опросник ригидности Г.В. Залевского (ТОРЗ). Сибирский психологический журнал, 12, 129-137.

Кон, И. (2009). Мужчина в меняюшемся мире. М.: Время.

Корнилова, Т. В., Чумакова, М. А. (2014). Шкалы толерантности и интолерантности к неопределенности в модификации опросника С. Баднера. Экспериментальная психология, 7(1), 92-110.

Крюкова, Т. Л. (2014). Динамические аспекты совладания, ориентированного на близкие межличностные отношения (партнерство, супружество). Вестник Костромского государственного университета. Серия Педагогика. Психология. Социокинетика, 20(2), 54-62.

Леонтьев, Д. А., Осин, Е. Н., Луковицкая, Е. Г. (2016). Диагностика толерантности к неопределенности: Шкалы Д. Маклейна. М.: Смысл.

Манукян, В. Р., Муртазина, И. Р., Гришина, Н. В. (2020). Опросник для диагностики потенциала самоизменений личности. Консультативная психология и психотерапия, 28(4), 35-58. https://doi.org/10.17759/cpp.2020280403

Петровский, В. А. (2018). Импликативная модель целеполагания: константы адаптивного действия. В кн. А. Г. Асмолов (ред.), Mobilis in mobili: личность в эпоху перемен (с. 331-362). М.: ИД ЯСК.

Пивовар, Б. Б. (2020). Управление изменениями в образовании: теория и практика. Образовательная политика, 2(82), 86-98. https://doi.org/10.22394/2078-838X-2020-2-86-98

Поддьяков, А. Н. (2001). Развитие исследовательской инициативности в детском возрасте [Докторская диссертация, МГУ им. М. В. Ломоносова].

Рассказова, Е. И., Гордеева, Т. О., Осин, Е. Н. (2013). Копинг-стратегии в структуре деятельности и саморегуляции: психометрические характеристики и возможности применения методики СОРЕ. Психология. Журнал Высшей школь экономики, 10(1), 82-118.

Сапронов, Д. В., Леонтьев, Д. А. (2007). Личностный динамизм и его диагностика. Психологическал диагностика, 1, 66-84.

Старовойтенко, Е. Б., Щебетенко, С. А. (2020). Я-Неизвестное в достижении самотождества и самопреобразовании личности. Психология. Журнал Высшей школь экономики, 17(4), 757-778. https://doi.org/10.17323/1813-8918-2020-4-757-778

Ссылки на зарубежные источники см. в разделе References после англоязычного блока.

Битюцкая Екатерина Владиславовна - доцент, кафедра общей психологии, факультет психологии, МГУ имени М.В. Ломоносова, кандидат психологических наук.

Сфера научных интересов: общая психология, психология преодоления трудных жизненных ситуаций, психодиагностика.

Контакты: bityutskaya_ew@mail.ru

Базаров Тахир Юсупович - профессор, кафедра социальной психологии, факультет психологии, МГУ имени М.В. Ломоносова, доктор психологических наук, профессор.

Сфера научных интересов: психология менеджмента, социальная психология лидерства и управления персоналом, теория и практика переговоров.

Контакты: tbazarov@mail.ru

Корнеев Алексей Андреевич - старший научный сотрудник, лаборатория нейропсихологии, факультет психологии МГУ имени М.В. Ломоносова, кандидат психологических наук. Сфера научных интересов: когнитивная психология, экспериментальная психология, нейропсихология, статистические методы обработки данных в психологии.

Контакты: korneeff@gmail.com 


\title{
The New Questionnaire “Types of Response to a Changing Situation”: The Structure of Scales and Psychometric Characteristics
}

\author{
E.V. Bityutskaya ${ }^{a}$, T.Yu. Bazarova, A.A. Korneev ${ }^{a}$ \\ ${ }^{a}$ Lomonosov Moscow State University, 1 Leninskie Gory, Moscow, 119991, Russian Federation
}

\begin{abstract}
The article presents the results of the psychometric analysis of the new questionnaire "Types of response to a changing situation". It is shown that the majority of modern questionnaires diagnose stable characteristics of response to changes and tolerance to uncertainty. At the same time, the new questionnaire is a situational type technique that allows one to study the dynamic properties. In the study conducted on a sample of 565 adult respondents, a factor structure was developed; age and gender characteristics of response to a changing situation were determined, as well as questionnaire convergent validity. Confirmatory factor analysis, descriptive statistics, Cronbach's alpha coefficient, correlation analysis, Shapiro-Wilk test, t-test were used in the work. The resulting questionnaire includes 48 items, which suggests an assessment on the Likert scale. The questionnaire has good psychometric properties. The questionnaire reliably measures seven strategies for responding to a changing situation, which fall into two types: acceptance (1) and rejection (2) of change. The first type includes 1) Mastering of changes, 2) Overcoming constraints, 3) Desire for changes, 4) Preferring uncertainty. The second type includes 1) Avoiding changes; 2) Preventing changes; 3) Maintaining stability. When comparing the indicators of strategies for age groups (17-24 years old and 25-67 years old), no significant differences were found. This may be due to the predominance of young adults in the sample of approbation. Analysis of gender differences showed that women more often report strong negative emotions, internal resistance in a situation of life changes. Men are more likely to indicate a preference for uncertain situations. The novelty of the questionnaire is associated with the ability to operationalize strategies for responding to changes as changing the way of interacting with a life situation.
\end{abstract}

Keywords: changing situation, acceptance-rejection of changes, strategy of response to a changing situation, perception of the situation.

\section{References}

Asmolov, A. G. (2015). Psychology of modernity: the challenges of uncertainty, complexity and diversity. Psikhologicheskie Issledovaniya, 8(40), 1. http://psystudy.ru/index.php/eng/2015v8n40e/ 1121-asmolov40e.html (in Russian)

Asmolov, A. G. (Ed.). (2018). Mobilis in mobili: lichnost'v epokhu peremen [Mobilis in mobile: personality in the age of change]. Moscow: YaSK.

Bazarov, T. Yu. (2007). Psikhologicheskie grani izmenyayushcheisya organizatsii [Psychological aspects of a changing organization]. Moscow: Aspekt press.

The reported study was funded by RFBR, project number 20-013-00838. 
Bazarov, T. Yu., \& Bityutskaya, E. V. (2020). Razrabotka novogo oprosnika Tipy reagirovaniya na situatsiyu izmenenii (TRSI) [The development of a new questionnaire "Types of response to a changing situation" (TRCS)]. In Anan'erskie chteniya - 2020. Psikhologiya sluzhebnoi deyatel'nosti: dostizheniya i perspektivy razvitiya (v chest' 75-letiya Pobedy v Velikoi Otechestvennoi voine 1941-1945 gg.): Materialy Mezhdunarodnoi nauchnoi konferentsii [Ananiev's Readings - 2020. The psychology of service duty: achievements and perspectives of growth (in honor of the 75 years since the Victory Day in the Great Patriotic War 1941-1945): Proceedings of the International Scientific Conference] (pp. 619-620). Saint Petersburg: Skifiya-print.

Bazarov, T. Yu., \& Sycheva, M. P. (2012). Development and approbation of Change Response Styles Questionnaire. Psikhologicheskie Issledovaniya, 5(25), 12. http://psystudy.ru/index.php/eng/ 2012v5n25e/737-bazarov25e.html (in Russian)

Bityutskaya, E. V. (2015). Oprosnik sposobov kopinga [The questionnaire of coping strategies]. Moscow: IIU MGOU.

Bityutskaya, E. V. (2020a). Meaning of threat and threat to meaning: modeling the perception of the pandemic COVID-19 situation. Vestnik Moskovskogo Gosudarstvennogo Oblastnogo Universiteta. Seriya Psikhologicheskie Nauki, 4, 21-39. https://doi.org/10.18384/2310-7235-2020-4-21-39 (in Russian)

Bityutskaya, E. V. (2020b). Chelovek i situatsiya neopredelennosti: strategii vzaimodeistviya [A person and the situation of uncertainty: strategies of interactions]. In E. S. Asmakovets (Ed.), Lichnost' professionala: razvitie, obrazovanie, zdorov'e: Sbornik nauchnykh statei. Omsk. Kel'tse. Plovdiv [Personality of a professional: growth, education, health: collection of scientific articles] (Iss. 5, pp. 44-50). Omsk: Izdatel'skii tsentr KAN.

Bityutskaya, E. V., \& Bazarov, T. Yu. (2019). Features of perception of life events by people with different preferred styles of response to changes. Voprosy Psikhologii, 3, 94-106. (in Russian)

Bityutskaya, E. V., \& Korneev, A. A. (2020). Diagnostics of perception of life events: the situational version of the questionnaire "Types of orientations in difficult situation". Bulletin of the Moscow Region State University (electronic journal), 4, 141-163. http://doi.org/10.18384/2224-02092020-4-1047 (in Russian)

Furnham, A., \& Marks, J. (2013). Tolerance of ambiguity: A review of the recent literature. Psychology, 4(9), 717-728. https://doi.org/10.4236/psych.2013.49102

Grishina, N. V. (2018). "Self-changes" of person: Possible and necessary. Vestnik of Saint Petersburg University. Psychology and Education, 8(2), 126-138. https://doi.org/10.21638/11701/ spbu16.2018.202 (in Russian)

Grishina, N. V. (Ed.). (2019). Psikhologiya lichnosti: Prebyvanie v izmenenii [The psychology of personality: Staying in flux]. Saint Petersburg: Saint Petersburg State University.

Gusev, A. I. (2011). Tolerantnost' k neopredelennosti kak sostavlyayushchaya lichnostnogo potentsiala [Tolerance to uncertainty as an element of personal potential]. In D. A. Leontiev (Ed.), Lichnostnyi potentsial: struktura i diagnostika [Personal potential: Structure and diagnostics] (pp. 300-329). Moscow: Smysl.

Kon, I. (2009). Muzhchina v menyayushchemsya mire [Man in a changing world]. Moscow: Vremya.

Kornilova, T. V., \& Chumakova, M. A. (2014). Tolerance and intolerance of ambiguity in the modification of Budner's questionnaire. Eksperimental'nas psihologis [Experimental Psychology (Russia)], 7(1), 92-110. (in Russian)

Kryukova, T. L. (2014). Dinamicheskie aspekty sovladaniya, orientirovannogo na blizkie mezhlichnostnye otnosheniya (partnerstvo, supruzhestvo) [Dynamic aspects of coping oriented to close and interpersonal relationships (partnership, marriage)]. Vestnik Kostromskogo Gosudarstvennogo Universiteta. Seriya Pedagogika. Psikhologiya. Sotsiokinetika, 20(2), 54-62. 
Leontiev, D. A., Osin, E. N., \& Lukovitskaya, E. G. (2016). Diagnostika tolerantnosti k neopredelennosti: Shkaly D. Makleina [Diagnostics of tolerance to uncertainty: D. McLain's scales]. Moscow: Smysl.

Manukyan, V. R., Murtazina, I. R., \& Grishina, N. V. (2020). Questionnaire for assessing the selfchange potential of a person. Konsul'tativnaya Psikhologiya i Psikhoterapiya [Counseling Psychology and Psychotherapy], 28(4), 35-58. https://doi.org.10.17759/cpp.2020280403. (in Russian)

Muthén, L. K., \& Muthén, B. O. (2012). Mplus user's guide (7th ed.). Los Angeles, CA: Muthén \& Muthén.

Norton, R. W. (1975). Measure of ambiguity tolerance. Journal of Personality Assessment, 39(6), 607-619. https://doi.org/10.1207/s15327752jpa3906_11

Petrovsky, V. A. (2018). Implikativnaya model' tselepolaganiya: konstanty adaptivnogo deistviya [Implicational model of goal-setting: constants of adaptive action]. In A. G. Asmolov (Ed.), Mobilis in mobili: lichnost'v epokhu peremen [Mobilis in mobile: Personality in the age of change] (pp. 331-362). Moscow: ID YaSK.

Pivovar, B. B. (2020). Upravlenie izmeneniyami v obrazovanii: teoriya i praktika [Management of changes in education: theory and practice]. Obrazovatel'naya Politika, 2(82), 86-98. https://doi.org/10.22394/2078-838X-2020-2-86-98

Poddyakov, A. N. (2001). Razvitie issledovatel'skoi initsiativnosti v detskom vozraste [Development of zeal for search in childhood] [Doctoral dissertation, Lomonosov Moscow State University].

Rasskazova, E. I., Gordeeva, T. O., \& Osin, E. N. (2013). Coping strategies in the structure of activity and self-regulation: psychometric properties and applications of the cope inventory. Psychology. Journal of Higher School of Economics, 10(1), 82-118. (in Russian)

Sapronov, D. V., \& Leontiev, D. A. (2007). Lichnostnyi dinamizm i ego diagnostika [Personal dynamism and its diagnostics]. Psikhologicheskaya Diagnostika, 1, 66-84.

Starovoytenko, E. B., \& Shchebetenko, S. A. (2020). Unknown self in reaching self-identity and selftransformation. Psychology. Journal of Higher School of Economics, 17(4), 757-778. https://doi.org/10.17323/1813-8918-2020-4-757-778 (in Russian)

Zalevskii, G. V. (2000). Tomskii oprosnik rigidnosti G.V. Zalevskogo (TORZ) [Tomsk questionnaire of rigity by G.V. Zalevskii (TQRZ)]. Siberian Journal of Psychology, 12, 129-137.

Ekaterina V. Bityutskaya - Associate Professor, Department of General Psychology, Faculty of Psychology, Lomonosov Moscow State University, PhD in Psychology.

Research Area: general psychology, coping psychology, psychodiagnostics.

E-mail: bityutskaya_ew@mail.ru

Tahir Yu. Bazarov - Professor, Department of Social Psychology, Faculty of Psychology, Lomonosov Moscow State University, DSc in Psychology, Professor.

Research Area: psychology of management, social psychology of leadership, negotiations theory and practice.

E-mail: tbazarov@mail.ru

Aleksei A. Korneev - Senior Researcher, Laboratory of Neuropsychology, Faculty of Psychology, Lomonosov Moscow State University, PhD in Psychology.

Research Area: cognitive psychology, experimental psychology, neuropsychology, statistical methods in psychology.

E-mail: korneeff@gmail.com 